\title{
صيغ الأمر ومعناه في سورة لقمان
}

\author{
| - (إعداد \\ ستي خديجة
}

\section{تجريد}

معاني الأمر في القرآن أما أصل وأما غير الأصل ـ لذلك يحتاج إلي التفسير

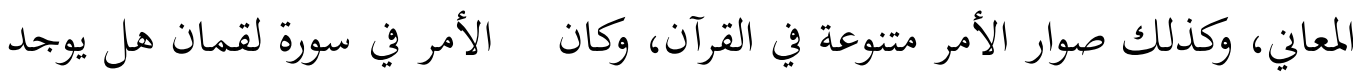

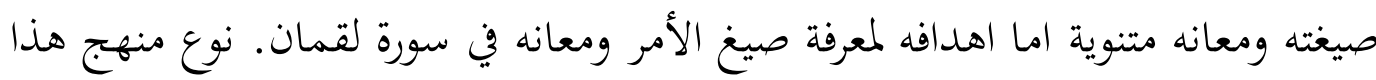
البحث دراسة مكتبية. ولذالك تبحث الباحثة وتحلل جميع الأمر في سورة لقمان لمعرفة صيغ الأمر ومعانه عند دراسة علم النحو. وآلة تحليل البيانات هي طريقة التحليل

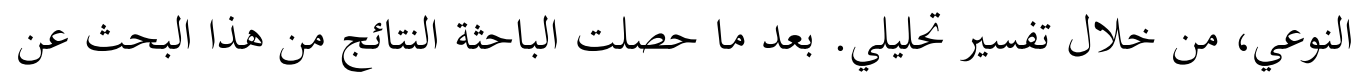

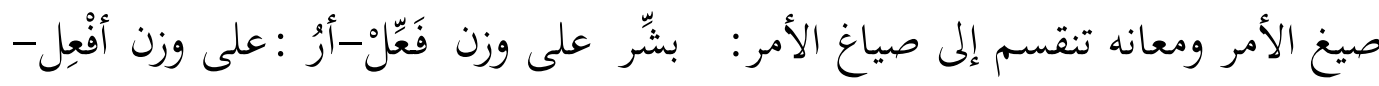

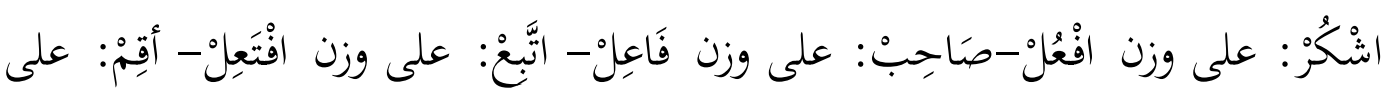

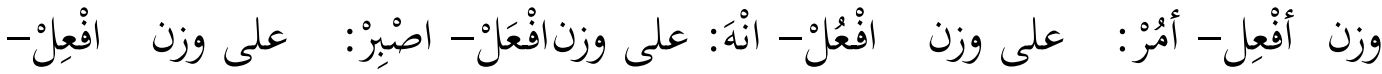

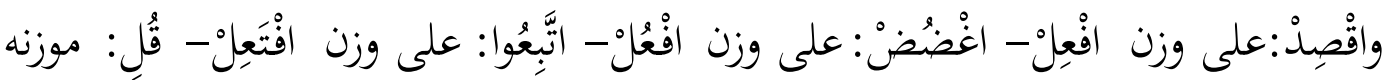

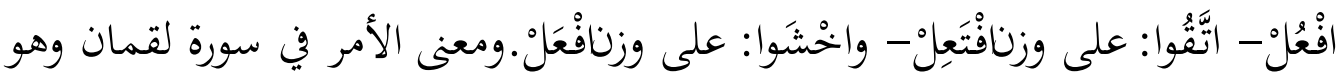
الإهانة، التعجير، الإمتنان، الإرشاد، الدوام، التأديب. الكلمة المحتوحة : صيغ الأمر ومعناه في سورة لقمان.

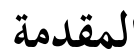

اللغة العربية وسيلة لشخص ما لفهم المعنى الوارد في القرآن. اللغة العربية تستخدم كمرجع في فهم القرآن وتفسيره.راى القسمي اللغة العربية في القرآن هو اللغة العربية تستخدم وتعرف في نزول القرآن دون نظر تطور اللغة العبية في هذا العصر. 
إن القرآن اعظم معجزات النبي صلى الله عليه وسلم حجة على نبوته وبرهانا على صدق رسالته، وكان القرآن مصدر الدين ومنبع من منابع العلوم ومعارف في الأرض

القرآن في اللغة فهي من مصدر (قرأ). يقال: قرأ- يقرأ- قرأ- قراءة- قرآنا ' ـ ثم نقل من هذا المعنى المصدرى، وجعل إسما للكالام المعجز المنزل على البي صلى الله عليه وسلم، من باب المصدر على مفعوله. فالقرآن على هذا يكون بمعنى المقروء'.

القرآن على الأصح لغة هو المصدر على وجه فعلان، كالغفران، بمعنى القراءة.

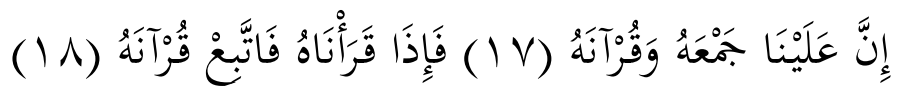

وفي الإصطالح هو الكالام الله تعإلى المنزل على نبينا(محمد) صلى الله عليه وسلم، المكتوب في المصاحف، المنقول الينا نقلا متواترا، المتعبد بتلاوته، المتحدي بأقصر سورة منه.

وأشهر تعريف له قولهم: القرآن كالم الله المعجز، المنزل على محمد صلى الله عليه وسلم، في المصاحف، المنقول بالتواتر المتعبد بتلاوته. تعليمات وإرشادات القران لها علاقة وإرتباط مع المبادئ التي يحتاجها الإنسان لنيل سعادهم في الدارين. فمن أراد أن يفهم القران تماما فلا بد عليه أن يقرأ ويطالع كتب التفاسير كما سار عليه المتقدمون. علم النحوهو العلم الذي يجب أن يتقن لتمكن فهم قوا عد تركيب الجمل باللغة العربية ولا شك ولا ريب بأنا لها أنماط الكلمة مع أنماط اللغة الإندونيسية.

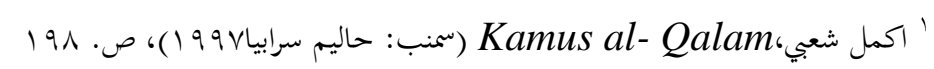

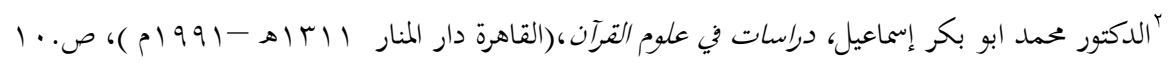

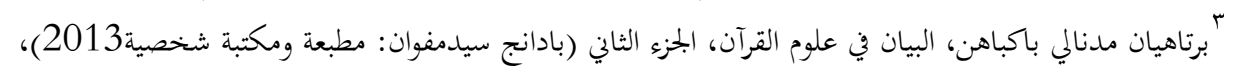


لأها لا تتحدث عن حالة صياغة الجملة فقط بل تتحدث أيضا عن حالة حرف عران أخير الكلمة مختلفة فإن المعنى كذالك مختلف كالمثل التي ذكرناها. ولذلك كان علم النحوبأمس الحاجة إليه في معرفة تغيير حركة الكلمة، لأن علم النحونوع من أنواع العلوم العربية الذي يتكلم فيه عن كيفية تركيب الكلمة

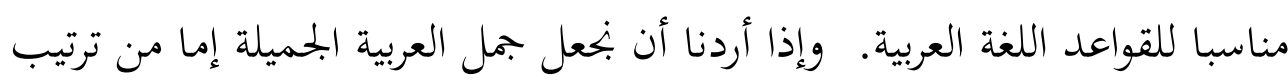

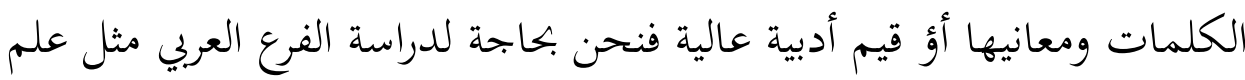
البالاغة لجمال اللغة علم المعاني وفهم العلم للنص وفقا السياق وعلم عرض شاعر لغة العربية. الأمر في اللغة معروف وهو ضد النهي كالإمار والإيمار بكسرهما. لِيقال: واحد

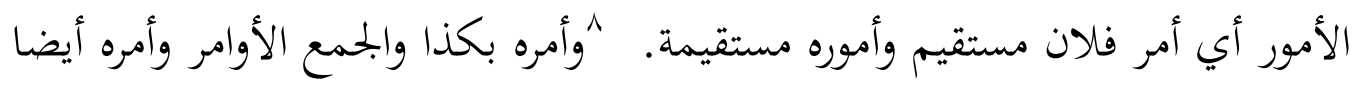

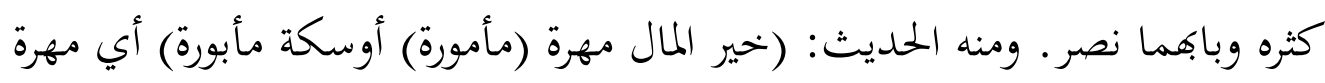

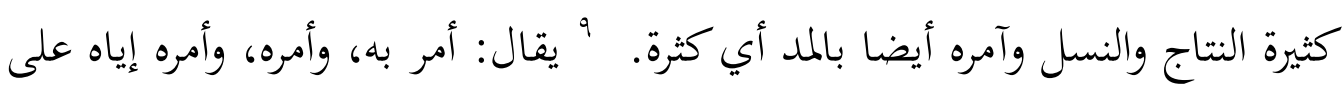

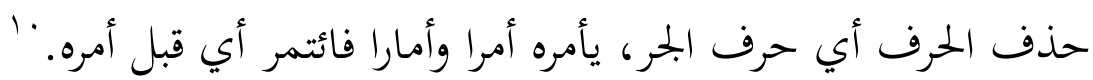

وفي معجم العين الأمر: نقيض النهى، والأمر واحد من أمور الناس. وإذا

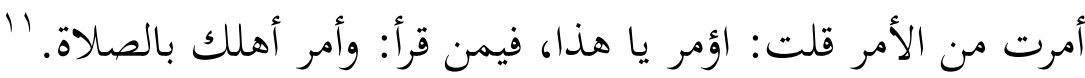

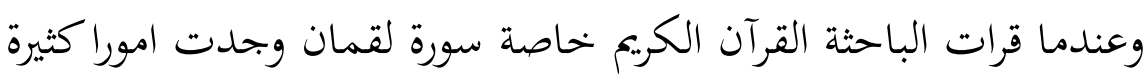
تتعلق بعلم النحووالبلاغة. كان فيه صيغة الأمر ومعناه.

\section{"نفس المراجع، دراسات في علوم القرآن، ص. 11

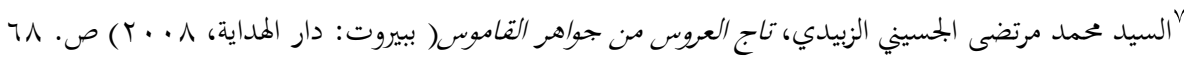

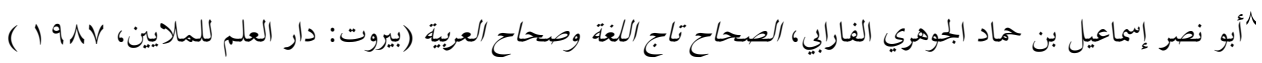

“و زين الدين أبو عبد الله محمد بن أبي بكر بن عبد القادر الحنفي الرازي، خختار الصحاح (بيروت :المكتبة

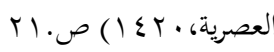

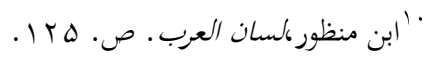

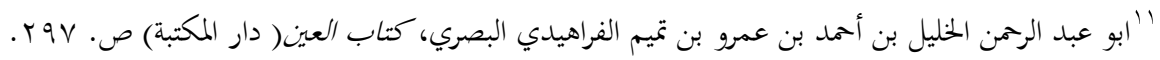




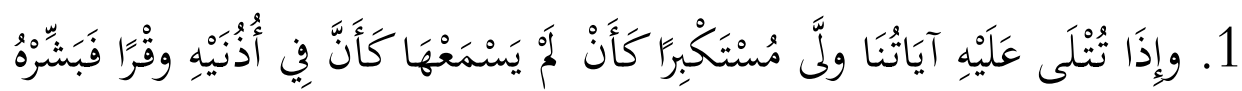

$$
\text { بِعَذَابِ أَلَيمٍ فالأمر في هذه الآية: بَشِّر }
$$

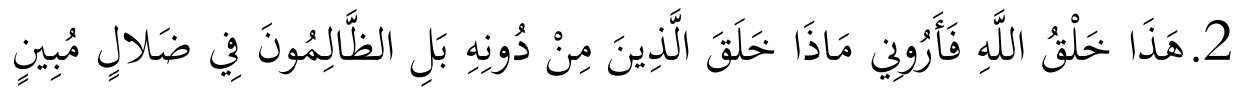

$$
\text { فالأمر في هذه الآية:أرُ }
$$

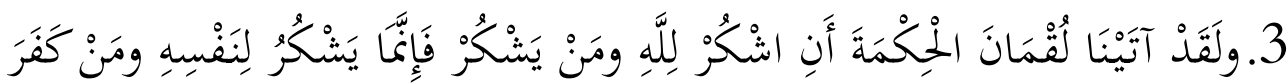

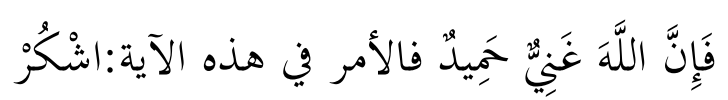

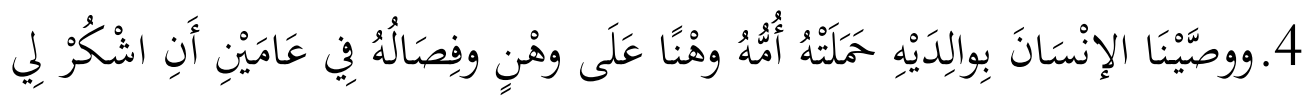

$$
\text { ولِوالِدَيْكَ إِلََََّ الْمَصِيرُ فالأمر في هذه الآية:انْكُرْ }
$$

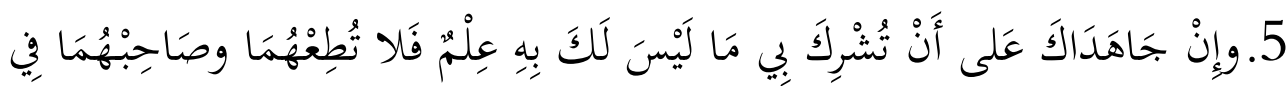

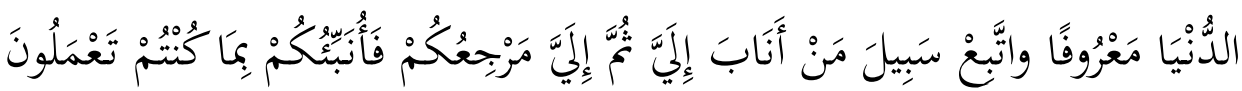

$$
\text { فالأمر في هذه الآية: صَاحِبْ }
$$

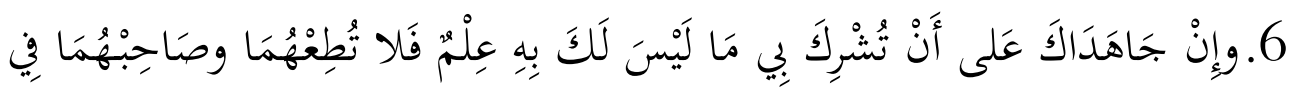

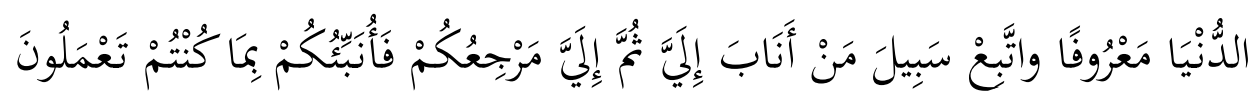

$$
\text { فالأمر في هذه الآية: اتَّبْْ }
$$




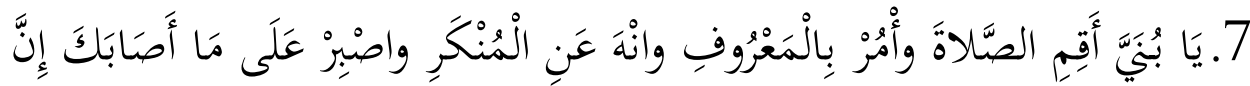
ذَلِكَ مِنْ عَزْجر الأمُورِ فالأمر في هذه الآية: أقِقْم

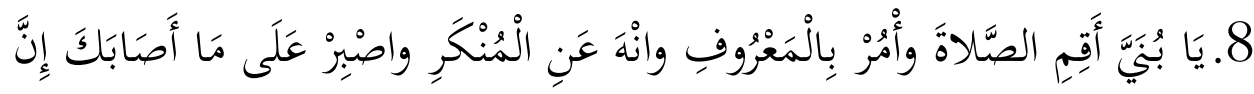

$$
\text { ذَلِكَ مِنْ عَنْج فالأمر في هذه الآية: أُمُر }
$$

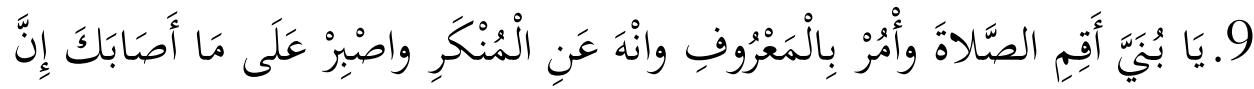

$$
\text { ذَلِكَ مِنْ عَزْم فالأمر في هذه الآية:وانْهَ }
$$

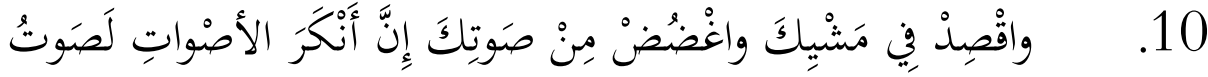

$$
\text { الحُمِيِِ فالأمر في هذه الآية:وَأَقِصِد }
$$

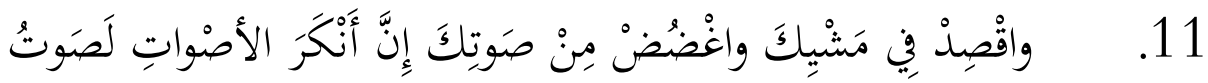

$$
\text { الحُمِيرِفالأمر في هذه الآية:واغْضُضْ }
$$

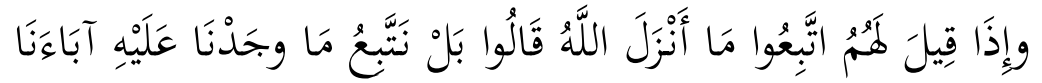

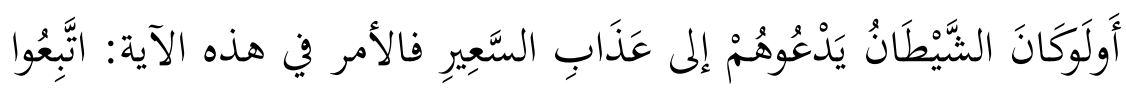

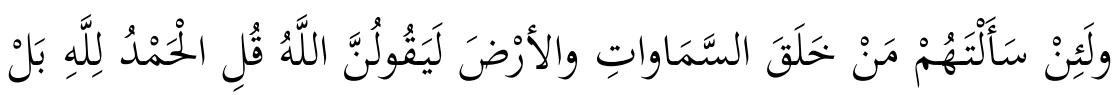

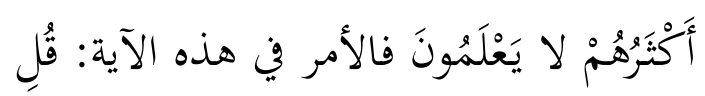

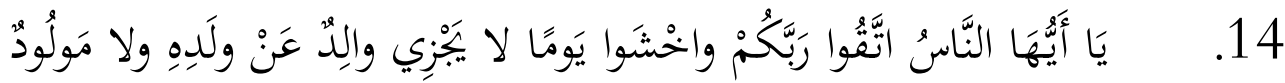

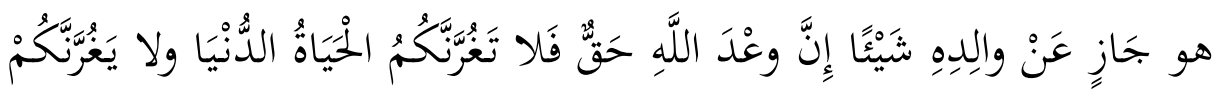

$$
\text { بِاللَّهِ الْغَرُورُ فالأمر في هذه الآية:اتَنَّو ا }
$$




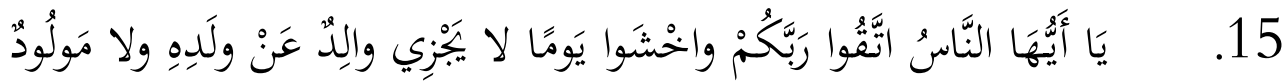

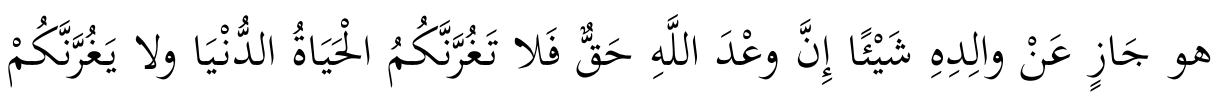
بِاللَّهِ الْغرُورُ فالأمر في هذه الآية:فالأمر في هذه الآية:وَاَخْشَوَا صيغة الفعل الأمر في سورة لقمان

1. بَثِّر: صيغة فَعِّل، وهي فعل مزيد الثلاثي بحرف على شكل: فَعَّلَ - يُفَعِّهُ -

فَعَعِّن

2. أُرُ :صيغة أفْعِلَ، وهي فعل مزيد الثلاثي بحرف على شكل: أفْعَل - يُفْعِلُ أَفْعِنْ

3. اشْكُرْ: صيغة افْعُعل، وهي الفعل البحرد الثلاثي على شكل: فَعَلَ - يَفْعُلُ -

\section{افْعُلو}

4. اشْكُرْ: : صيغة افْعُلْ، وهي الفعل البحرد الثلاثي على شكل: فَعَلَ - يَفْعُلُ -

افْعُحُ

5. صَاحِبْ: صيغة فَاعِلْ، وهي فعل مزيد الثلاثي بحرف على شكل: فَاعَلَ -

$$
\text { يُفَاعِلُ - فَاعِلْ }
$$

6. اتَّبعْ: صيغة افْتَعِلْ، وهي فعل مزيد الثنلاثي بحرفين على شكل: افْتَعَل - يَفْتَعِلُ

$$
\text { - افْتَعِلْ }
$$

7. أقِمْم: صيغة أفْعِلَ، وهي فعل مزيد الثلاثي بحرف على شكل: أفْعَلَ - يُفْعِلُ - 
8. أمُرْ: صيغة افْعُلْ، وهي الفعل المُحرد الثلاثي على شكل: فَعَلَ - يَفْعُلُ - افْعُلْ 9. انْهَ: صيغة افْعَلْ، وهي الفعل المُحرد الثلاثي على شكل: فَعَلَ - يَفْعَلُ - افْعَلْ 10. اصْبِر: صيغة افْعِلْ، وهي الفعل البحرد الثلاثي على شكل: فَعَلَ - يَفْعِلُ - افْعِلْ

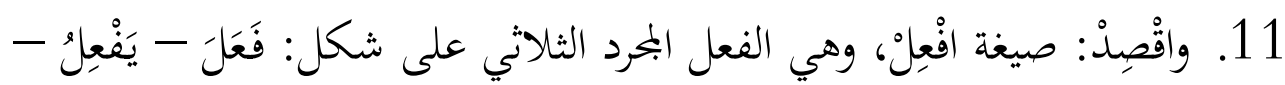

افْعِلْ

12. اغْضُضْ:صيغة افْعُلْ، وهي الفعل المحرد الثلاثي على شكل: فَفَلَ - يَفْعُله افْعُلْ 13. اتَّبَعُوا :صيغة افْتَعِلْ، وهي فعل مزيد الثلاثي بحرفين على شكل: افْتَعَلَ - يَفْتَعِلُ

$$
\text { افْتَعْلْ - }
$$

14. قُلِّ: صيغة افْعُلْ، وهي الفعل المُرد الثلاثي على شكل: فَعَلَ - يَفْعُلُ - افْعُلْ

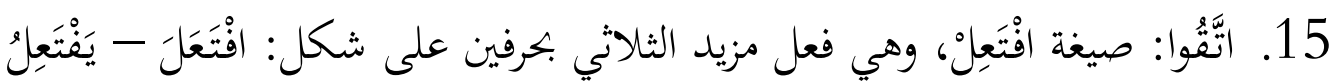

$$
\text { - افْتَعَلْ - }
$$

16. واخْشَوا: صيغة افْعَلْ، وهي الفعل المحرد الثلاثي على شكل: فَعَلَ - يَفْعَلُ افْعَلْ

\section{إعراب الفعل الأمر في سورة لقمان}

1. بَشّرّ : فعل أمر مبني على السكون لأنه صحيح الآخر، وفاعله ضمير مستتر فيه

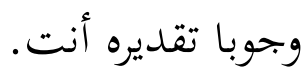


2. أرُ: فعل أمر مبني على حذف النون لاتصاله بواو الجماعة، والواو: ضمير متصل

$$
\text { مبني على السكون في محل رفع فاعل. }
$$

3. اشْكُرْ: : فعل أمر مبني على السكون لأنه صحيح الآخر، وفاعله ضمير مستتر

$$
\text { فيه وجوبا تقديره أنت. }
$$

4. اشْكُرْ: : فعل أمر مبني على السكون لأنه صحيح الآخر، وفاعله ضمير مستتر

$$
\text { فيه وجوبا تقديره أنت. }
$$

5. صَاحِبْ : فعل أمر مبني على السكون لأنه صحيح الآخر، وفاعله ضمير

$$
\text { مستتر فيه وجوبا تقديره أنت. }
$$

6. اتَّبْْ: : فعل أمر مبني على السكون لأنه صحيح الآخر، وفاعله ضمير مستتر فيه

$$
\text { وجوبا تقديره أنت. }
$$

7. أقِمْ: فعل أمر مبني على السكون لأنه صحيح الآخر، وفاعله ضمير مستتر فيه

$$
\text { وجوبا تقديره أنت. }
$$

8. أمُرْ: : فعل أمر مبني على السكون لأنه صحيح الآخر، وفاعله ضمير مستتر فيه

$$
\text { وجوبا تقديره أنت. }
$$

9. اصْبرٌ: فعل أمر مبني على السكون لأنه صحيح الآخر، وفاعله ضمير مستتر فيه

$$
\text { وجوبا تقديره أنت. }
$$

$$
\text { مستتر فيه وجوبا تقديره أنت. }
$$

11. اقْصِد: فعل أمر مبني على السكون لأنه صحيح الآخر، وفاعله ضمير

$$
\text { مستتر فيه وجوبا تقديره أنت. }
$$


(9) Jurnal Thariqah Ilmiah Vol. 07 No. 02 Desember 2019

$$
\begin{aligned}
& \text { 12. اغْضُضْ: فعل أمر مبني على السكون لأنه صحيح الآخر، وفاعله } \\
& \text { ضمير مستتر فيه وجوبا تقديره أنت. }
\end{aligned}
$$

أَبَّعُوا: : فعل أمر مبني على حذف النون لاتصاله بواو الجماعة، والواو :

ضمير متصل مبني على السكون في محل رفع فاعل، والألف: زائدة فارقة.

14. قُّل: فعل أمر مبني على السكون لأنه صحيح الآخر، وفاعله ضمير

$$
\text { مستتر فيه وجوبا تقديره أنت. }
$$

15. اتَّقوا: فعل أمر مبني على حذف النون لاتصاله بواو الجماعة، والواو :

ضمير متصل مبني على السكون في محل رفع فاعل، والألف: زائدة فارقة.

انْشَوا: فعل أمر مبني على حذف النون لاتصاله بواو الجماعة، والواو: ضمير

متصل مبني على السكون في محل رفع فاعل، والألف: زائدة فارقة.

\section{هـ-معاني الفعل الأمر في سورة لقمان}

1. بَشِّر: ومعنى الفعل الأمر هنا هي: الإهانة، لأن بشارة هنا تؤثر في قلبه الحزن

$$
\text { والغم; وين بشرته السوء والظلمة والغبرة. }
$$

2. أرُ : ومعنى الفعل الأمر هنا هي: التعجيز، لأن المعلوم أهم لا يقدرون وأنيروه شيئا من الخلق لما، لأن جميع المذكورات، قد أقروا أها خلق الله وحده.

3. اشْكُرٌ : ومعنى الفعل الأمر هنا هي: الامتنان، لأن الله تعإلى قد أعطاه الله هذه المنة العظيمة فأمره أن يشكره على ما أعطاه، ليبارك له فيه، وليزيده من فضله، وأخبره أن شكر الشاكرين، يعود نفعه عليهم، وأن من كفر فلم يشكر لله، عاد وبال ذلك عليه.

4. اشْكُرٌ : ومعنى الفعل الأمر هنا هي: الامتنان، لأن الله تعإلى قد أعطاه الله هذه المنة العظيمة فأمره أن يشكره على ما أعطاه، ليبارك له فيه، وليزيده من فضله، 
وأخبره أن شكر الشاكرين، يعود نفعه عليهم، وأن من كفر فلم يشكر لله، عاد

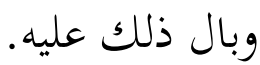

5. صَاحِبْ : ومعنى الفعل الأمر هنا هي: الإرشاد، لأن فيها إرشاد لفعل صحبة

$$
\text { إحسان إلى الوالدين بالمعروف. }
$$

6. اتَّْْْ : ومعنى الفعل الأمر هنا هي: الإرشاد، لأن فيها إرشاد للتباع المؤمنين بالله، وملائكته وكتبه، ورسله، المستسلم، المنيبين إليه. 7. أقِمْ : ومعنى الفعل الأمر هنا هي: الدوام، لأن الصالاة متكرة في كل يوم وليلة. 8. أمُرْ : ومعنى الفعل الأمر هنا هي: الإرشاد، لأن فيها إرشاد لا لأمر بالمعروف أي أمر النفس والغير بما هو معروف شرعا وعقلا، كمكارم الأخلاق، ومحاسن الأفعال، مما يهذب النفس ويدعوإلى التحضر والتمدن.

9. انْهَ : ومعنى الفعل الأمر هنا هي: الإرشاد، لأن فيها إرشاد النهي عن المنكر، أي منع النفس والآخرين من المعاصي والمنكرات المحرّة شرعا والقبيحة عقلا، والتي

$$
\text { تغضب الله، وتوجب عذاب جهنم. }
$$

10. اصْبِر: ومعنى الفعل الأمر هنا هي: الإرشاد، لأن فيها إرشاد الصبر على الأذى والشدائد والأوامر الإلهية، فإن الآمر بالمعروف، والناهي عن المنكر يؤذى عادة،

$$
\text { فطلب منه الصبر. }
$$

11. واقْصِدْ: ومعنى الفعل الأمر هنا هي: التأديب، لأن فيها التأديب في المشي. أمر

بالمشي متوسطا وعدلا، ليس بالبطيء المتثبّط المتماوت الذي يظهر الضعف

$$
\text { تزهدا، ولابالسريع المفرط، الذي يثب وثب الشيطان. }
$$


12. اغْضُضْ:ومعنى الفعل الأمر هنا هي: التأديب، لأن فيها التأديب في الصوت، أدبا مع الناس ومع الله.

13. اتَّبعُوا: ومعنى الفعل الأمر هنا هي: الإرشاد، لأن فيها إرشاد للتباع ما أنزل الله

$$
\text { على أيدي رسله، فإنه الحق، وبينت لهم أدته الظاهرة. }
$$

14. قُلْ: ومعنى الفعل الأمر هنا هي: الامتنان، لقولك: الحمد لله على اعترافكم، إذ قامت الحجة عليكم بإلجائكم إليه، وأن دلائل التوحيد واضحة، لايكاد ينكرها أحد.

15. اتَّقُوا:معنى الفعل الأمر هنا هي: الإرشاد، لأن الله يأمر الناس بتقواه، التي هي امتثال أوامره، وترك زواجره، ويستلفتهم لخشية يوم القيامة، اليوم الشديد، الذي

$$
\text { فيه كل أحدلايهمه إلانفسه. }
$$

16. واخْشَوا: ومعنى الفعل الأمر هنا هي: الإرشاد، لأن فيها إرشاد لخشية يوم شديد الهو ل هو يوم القيامة الذي لا يغني فيه والد عن ولده، فلوأراد أن يفديه بنفسه لما قبل منه، ولا مولود هو مغن عن والده أونافع والده شيئا، فلوأراد فداء والده بنفسه، لم يقبل منه، إذلايستطيع أحد أن يشفع بأحد إلا بإذن الله.

الخلاصة

وجدت الباحثة في سورة لقمان خاصة و جدت الباحثة16 فعلا أمرا الأمر في سورة لقمان كله 16. وصيغة فعل الأمر في سورة لقمان يشتمل على صيغة المتنوعة. وإعراب

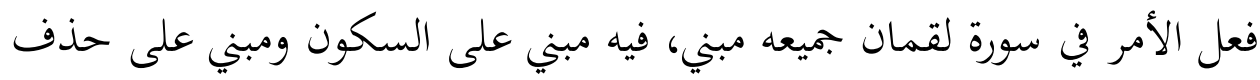

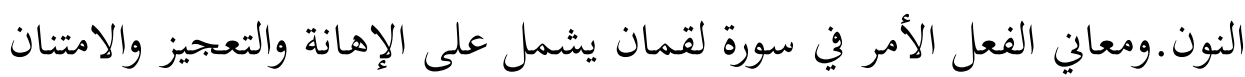
والإرشاد والدوام والتأديب. 


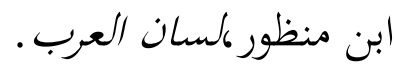

أبوعبد الرحمن الخليل بن أحمد بن عمروبن تميم الفراهيدي البصري، كتاب العين( دار

أبونصر إسماعيل بن حماد الجوهري الفارابي، الصحاح تاج اللغة وصحاح العببية (بيروت:

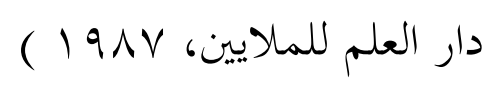

$$
\text { أكمل شعبي قموس الكلام،(سمنب: حاليم سرابيالو } 99 \text { 1) }
$$

برتاهيان مدنالي باكباهن، البيان في علوم القرآن، الجزء الثاني (بادانج سيدمفوان: مطبعة

$$
\text { ومكتبة شخصية 2013) }
$$

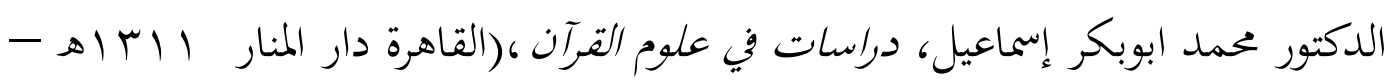

$$
\text { ( }) \text { ( } 99 \text { ) }
$$

زين الدين أبوعبد الله محمد بن أبي بكر بن عبد القادر الحنفي الرازي، مختار الصحاح

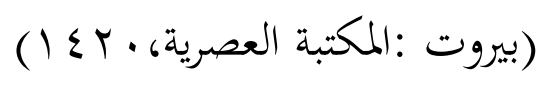

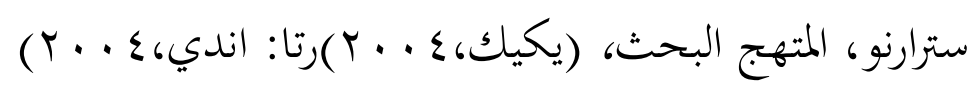

السيد محمد مرتضى الجسيني الزبيدي، تاج العروس من جواهر القاموس ( ببيروت: دار

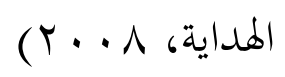

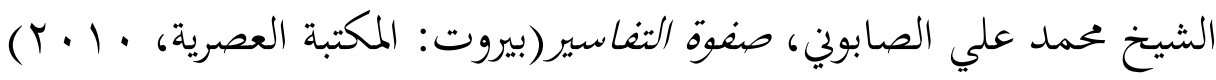

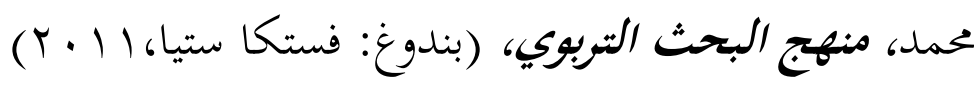


(13) Jurnal Thariqah Ilmiah Vol. 07 No. 02 Desember 2019 